\title{
ESCARIFICAÇÃO EM PLANTIO DIRETO COMO TÉCNICA DE CONSERVAÇÃO DO SOLO E DA ÁGUA ${ }^{(1)}$
}

\author{
Rodrigo Kurylo Camara ${ }^{(2)}$ \& Vilson Antonio Klein ${ }^{(3)}$
}

\begin{abstract}
RESUMO
O plantio direto (PD) é, comprovadamente, uma técnica de manejo do solo eficiente no controle à erosão, minimizando as perdas de solo. No entanto, o não-revolvimento do solo, aliado ao tráfego de máquinas, acarreta alterações na sua estrutura que, associada à reduzida rugosidade superficial, podem ser desfavoráveis à infiltração de água, modificando a sua dinâmica nesse sistema. O objetivo deste trabalho foi avaliar as alterações nas propriedades físico-hídricas do solo sob PD e plantio direto escarificado (PDE), após seis anos sob PD, e os efeitos de sulcadores de semeadoras-adubadoras no solo. Avaliaram-se a densidade do solo, a porosidade total, a macroporosidade e a infiltração da água no solo antes da semeadura da soja, a rugosidade superficial e o percentual da superfície do solo coberto com restos culturais antes e depois da semeadura e a condutividade hidráulica do solo saturado após 12 meses da escarificação. $O$ PDE apresentou uma densidade do solo menor que o PD e uma maior infiltração de água, condutividade hidráulica do solo saturado e rugosidade superficial, demonstrando ser uma técnica eficaz para melhorar a conservação do solo e da água, apresentando efeito residual da escarificação transcorrido um ano da operação. A porosidade total e a macroporosidade não apresentaram diferença significativa entre os manejos. Nos dois manejos, a cobertura do solo apresentouse similar antes da semeadura, isto é, após seis meses da escarificação. Durante a semeadura da soja, os mecanismos sulcadores de adubo apresentaram ação distinta, tendo o tipo guilhotina incorporado significativamente mais restos culturais do que o duplo disco.
\end{abstract}

Termos de indexação: infiltração de água, rugosidade superficial, mecanismos sulcadores.

\footnotetext{
(1) Parte da 'Tese de Mestrado do primeiro autor, financiada pela FAPERGS, processo $\mathrm{n}^{\circ}$ 01/1706.0. Recebido para publicação em março de 2004 e aprovado em julho de 2005.

(2) Engenheiro-Agronômo, Mestre em Agronomia, Área de Concentração Produção Vegetal. Faculdade de Agronomia e Medicina Veterinária, Universidade de Passo Fundo - FAMV/UPF. CEP 99001-970 Passo Fundo (RS). E-mail: rodrigokurylo@yahoo.com.br

${ }^{(3)}$ Professor Titular da FAMV/UPF. E-mail: vaklein@upf.br
} 


\title{
SUMMARY: CHISELING IN NO-TILLAGE SYSTEM AS SOIL AND WATER CONSERVATION PRACTICE
}

\begin{abstract}
No tillage (NT) is a proven and efficient soil management practice used to reduce soil erosion, minimizing soil losses. However, the absence of soil movement associated with traffic of heavy machinery cause changes in the soil structure, which combined with low surface roughness, can affect water dynamics by reducing the water infiltration rate. Our aim was to evaluate changes in soil properties under NT and chiseling in no tillage (CNT), as well as the effect of distinct planter furrow openers on soil characteristics. The following parameters were assessed: bulk and particle density, total porosity, macroporosity, water infiltration into soil prior to soybean planting, surface roughness, percentage of soil surface covered with crop residues before and after planting, and soil hydraulic conductivity after 12 months of chiseling. CNT showed a lower soil density than NT, higher water infiltration, higher saturated soil hydraulic conductivity, and higher surface roughness. Therefore, CNT improved soil and water conservation since there were still residual effects one year after chiseling. Total porosity and macroporosity did not differ significantly between the soil management systems. Soil cover was similar under both managements before planting, i.e., six months after chiseling; however, at soybean planting, the hoe-type planter provided better incorporation of crop residues into the soil than the double-disc type.
\end{abstract}

Index terms: water infiltration, surface roughness, seed drills.

\section{INTRODUÇÃO}

O sistema plantio direto (PD) foi desenvolvido com vistas em buscar a sustentabilidade da produção agrícola, mostrando-se comprovadamente eficiente no controle de erosão (Resck, 1999) e adequado para as regiões tropicais (Romeiro, 1998), evitando exposição do solo à intensa ação dos raios solares e da chuva. No entanto, o não-revolvimento do solo, aliado ao tráfego de máquinas, acarreta alterações na sua estrutura que, associadas à reduzida rugosidade superficial, podem ser desfavoráveis à infiltração de água, modificando sua dinâmica nesse sistema.

A descompactação do solo utilizando implementos de hastes, como escarificadores, que produzem superfícies mais rugosas, que os implementos de discos, como grades pesadas, tem por objetivo aumentar a porosidade, reduzir a densidade e, ao mesmo tempo, romper as camadas superficiais encrostadas e camadas subsuperficiais compactadas (Kochhann \& Denardin, 2000). O tipo e a época das operações de preparo influenciam o seu resultado, afetando a taxa de infiltração à velocidade da enxurrada, a capacidade de armazenamento de água no solo e, por conseqüência, os riscos de erosão (Levien et al.,1990).

As operações de preparo do solo, como a escarificação, criam um microrrelevo na superfície do solo, sendo o índice de rugosidade superficial do mesmo o critério mais utilizado para a sua determinação. Essas alterações afetam o escoamento superficial e o armazenamento temporal de água (Vazquez \& De Maria, 2003).

Estudos realizados por Boller (1990), Dallmeyer (1994) e Secco \& Reinert (1997) demonstraram o efeito de implementos de hastes sobre o aumento da rugosidade superficial. Destacaram que esse tipo de preparo aumentou de duas a quatro vezes a rugosidade superficial do solo em relação a outros manejos e que, mesmo com o passar do tempo, essa rugosidade manteve-se mais elevada.

A presença de restos culturais na superfície do solo, independentemente do manejo adotado, proporciona redução de perda de solo, enquanto a perda de água é mais afetada pela forma de manejo dos resíduos do que pela percentagem de cobertura morta sob o solo (Carvalho et al.,1990). Bertol et al. (1997) destacaram que um manejo com $60 \%$ de cobertura promove uma redução de $80 \%$ nas perdas de solo em relação ao manejo com ausência de cobertura.

Segundo Foster (1982), a cobertura do solo é o fator isolado que mais exerce influência sobre a erosão. Isso porque resíduos culturais ou plantas vivas diminuem o impacto das gotas de chuva, diminuindo a velocidade e o volume da enxurrada, além de promover a filtragem dos sedimentos grosseiros.

A cobertura do solo normalmente presente no plantio direto acumula maior teor de matéria orgânica próximo à superfície, aumentando a capacidade de retenção de água, especialmente em solos arenosos (Abrão et al., 1979), diminui as variações da temperatura do solo e a evaporação da água e eleva a taxa de infiltração (Bragagnolo \& Mielniczuck, 1990).

Segundo Cogo et al. (1984), a incorporação parcial de resíduos foi mais eficaz na redução de perdas de solo por erosão hídrica do que a sua manutenção na superfície. Segundo Denardin (1987), o preparo reduzido do solo com escarificador pode proporcionar 
este tipo de vantagem, ao manter consideráveis quantidades de restos culturais na superfície ou parcialmente incorporados.

Vários são os fatores que interferem na magnitude da infiltração de água no solo. Esses fatores estão associados às propriedades físicas do solo e do manejo adotado. Textura, estrutura, porosidade, rugosidade superficial, restos culturais, matéria orgânica, atividade biológica do solo (Gavande, 1986), manejo do solo e umidade inicial, além do método utilizado (Brito et al., 1996), são alguns dos fatores apontados como responsáveis pelas variações na taxa de infiltração.

Segundo Chaves et al. (1993), os repetidos impactos das gotas de chuva contribuem para a redução da taxa de infiltração por duas maneiras: diminuição da rugosidade superficial, reduzindo as chances de empoçamento, e a formação de uma fina camada adensada na superfície. Essa camada apresenta menor condutividade hidráulica e é responsável por reduções de até $90 \%$ da permeabilidade original. Segundo Cintra et al. (1983), a taxa de infiltração de água no solo é a característica mais sensível para detectar alterações induzidas pelo cultivo.

Diversos estudos demonstram o efeito negativo do preparo sobre a capacidade de infiltração da água no solo: Silva (1980) determinou uma taxa de infiltração de $1.125 \mathrm{~mm} \mathrm{~h}^{-1}$ para área com vegetação nativa e $2 \mathrm{~mm} \mathrm{~h}^{-1}$ para o preparo convencional. Castro et al. (1986), avaliando o efeito de sistemas de preparo do solo na infiltração da água, obtiveram uma taxa de infiltração de $12,8 \mathrm{~mm} \mathrm{~h}^{-1}$, quando utilizaram um arado de disco mais uma grade leve, enquanto obtiveram com o uso de escarificador $32,5 \mathrm{~mm} \mathrm{~h}^{-1}$. Destacam ainda o efeito da escarificação em profundidade, com pouco revolvimento do solo mantendo maior cobertura do solo por resíduos vegetais capaz de reduzir o escoamento superficial.

Eltz et al. (1989), avaliando sistemas de manejo de solo, como preparo convencional no inverno e PD no verão, concluíram que a taxa de infiltração de água foi cerca de cinco vezes menor no manejo convencional em relação ao $\mathrm{PD}$ e plantio direto escarificado no inverno.

Kertzmann (1996) obteve uma taxa constante de infiltração de água de $1.396 \mathrm{~mm} \mathrm{~h}^{-1} \mathrm{em}$ solo de mata, enquanto na área cultivada com PD por 15 anos a taxa foi de $63 \mathrm{~mm} \mathrm{~h}^{-1}$. Estes resultados demonstraram que houve uma drástica redução na taxa de infiltração, em mais de 20 vezes, de acordo com o manejo e cultivo adotado, em decorrência da intensificação de operações mecanizadas, em relação à condição natural.

O objetivo deste trabalho foi avaliar não só o efeito da escarificação esporádica em solo sob plantio direto sobre as propriedades físico-hídricas do solo, mas também o posterior efeito de mecanismos sulcadores de semeadoras-adubadoras na rugosidade superficial e cobertura do solo.

\section{MATERIAL E MÉTODOS}

O experimento foi instalado em uma área na região do planalto médio Riograndense com altitude média de $684 \mathrm{~m}$ e clima segundo a classificação de Koeppen, do tipo Cfa1 (subtropical chuvoso) num Latossolo Vermelho distrófico típico relevo ondulado e substrato basalto, com composição granulométrica do horizonte superficial de $0,61 \mathrm{~kg} \mathrm{~kg}^{-1}$ de argila, $0,10 \mathrm{~kg} \mathrm{~kg}^{-1}$ de silte e $0,29 \mathrm{~kg} \mathrm{~kg}^{-1}$ de areia.

A área vinha sendo cultivada sob sistema plantio direto contínuo por um período de seis anos com a seguinte seqüência de culturas: 1997/98 soja-trigo, 1998/99 soja-aveia, 1999/00 milho-aveia, 2000/01 soja-aveia, 2001/02 milho para silagem e milho. Após a colheita do milho, no mês de maio de 2002 , realizouse a escarificação em parte da área, utilizando escarificador modelo Jumbo-Matic, equipado com cinco hastes de formato parabólico, espaçadas em $33 \mathrm{~cm}$, discos de corte e rolo destorroador/nivelador, a uma profundidade média de $25 \mathrm{~cm}$. Após a escarificação, sem preparo complementar, semeouse aveia preta, com a finalidade de adubação verde, utilizando semeadora-adubadora modelo TD 220, equipada com disco duplo desencontrado.

O delineamento experimental foi em faixa com sete repetições, tendo, como parcelas principais, o sistema plantio direto (PD) e o sistema plantio direto escarificado (PDE). Foram considerados, como subparcelas, os mecanismos sulcadores: disco duplo desencontrado (DD) e guilhotina (G). Cada unidade experimental tinha dimensões de $3 \times 20 \mathrm{~m}$. Para a coleta das amostras de solo para a determinação das propriedades físicas do solo, utilizaram-se, como subparcelas, as profundidades de coleta $(2,5 ; 5,0$; 10,$0 ; 15,0 ; 20,0$ e $25,0 \mathrm{~cm}$ ).

As amostras de solo com estrutura preservada foram coletadas em cada unidade experimental seis meses após a escarificação (novembro de 2002), com auxílio de um amostrador do tipo "Uhland", utilizando cilindros de aço inoxidável com $5 \mathrm{~cm}$ de diâmetro e $5 \mathrm{~cm}$ de altura. Estas foram retiradas ao longo do perfil do solo nas profundidades e utilizadas para determinação da densidade do solo e da macroporosidade. Nessas profundidades, retiraram-se amostras que foram peneiradas em peneira com malha de $2 \mathrm{~mm}$, para a determinação da densidade de sólidos e composição granulométrica.

A determinação da densidade dos sólidos e do solo foi realizada conforme método descrito pela Embrapa (1997). A porosidade total foi determinada pela relação entre a densidade do solo e dos sólidos e a macroporosidade, submetendo as amostras com estrutura preservada à tensão de $6 \mathrm{kPa}$ em funis de placa porosa.

Transcorridos seis meses da escarificação (novembro de 2002), realizou-se a semeadura da 
soja, apresentando o solo uma umidade de $0,28 \mathrm{~kg} \mathrm{~kg}^{-1}$, a qual, segundo Boller (1990), para este solo é condição friável. Utilizou-se uma semeadoraadubadora modelo SHM 15, marca SEMEATO, com espaçamento nas entre linhas de $0,42 \mathrm{~m}$ que foi equipada com dois tipos de sulcadores para a abertura do sulco e deposição do adubo. O sulcador do tipo guilhotina $(\mathrm{G})$ consiste de um disco de corte do restos culturais e um cinzel sulcador, que operou a uma profundidade média de $12 \mathrm{~cm}$, enquanto $o$ duplo disco (DD) consiste de dois discos com diâmetros distintos que apresentam centros coincidentes, acarretando uma defasagem na parte posterior do disco, esse dispositivo operou a uma profundidade média de $7 \mathrm{~cm}$.

A rugosidade da superfície do solo foi determinada pelo uso de um perfilômetro semelhante ao descrito por Allmaras et al. (1966), com 90 hastes espaçadas de $5 \mathrm{~cm}$ entre si. Essas determinações foram efetuadas antes, depois da semeadura e depois da colheita, sempre no mesmo local. O cálculo do índice de rugosidade superficial foi efetuado pela fórmula sugerida por Selles, descrita por Boller (1990).

$$
\mathrm{IR}=\sum \mathrm{Y}^{2}-\sqrt{\frac{\left(\sum \mathrm{Y}\right)^{2}}{\mathrm{n}}}
$$

em que IR = Índice de rugosidade; $\mathrm{Y}=$ altura de cada haste; e $\mathrm{n}=$ número de leituras.

A percentagem do solo coberto com restos culturais, antes e depois da semeadura, foi determinada pelo método da trena marcada, descrito por Laflen et al. (1981). Consiste na utilização de uma trena de $10 \mathrm{~m}$, marcada a cada $0,1 \mathrm{~m}$, que é lançada sobre a parcela de forma aleatória e, pela contagem do número de marcas coincidentes com a palha no solo, obtém-se, de forma direta, a percentagem de cobertura do solo por resíduos vegetais.

O método utilizado para determinar a infiltração de água foi a inundação com duplo cilindro concêntrico de taxa constante equipados com bóia, tendo uma carga hidráulica constante de $50 \mathrm{~mm}$ até à obtenção da taxa constante de infiltração, determinada em cinco unidades experimentais. Os resultados obtidos foram ajustados à equação de Kostiakov (1932).

Após 12 meses da escarificação (maio 2003), coletaram-se amostras de solo com as quais foi determinada a condutividade hidráulica do solo saturado, conforme o método proposto pela Embrapa (1997), utilizando permeâmetro de carga constante.

Os resultados foram submetidos à análise da variância e, com $\mathrm{F}$ significativo, as médias foram comparadas pelo teste de Duncan. Para densidade e porosidade do solo, as profundidades foram consideradas parcelas subdivididas, enquanto, para rugosidade e cobertura do solo, os mecanismos sulcadores foram considerados as parcelas subdivididas. Para a infiltração da água no solo e condutividade hidráulica do solo saturado, utilizouse o teste $\mathrm{T}$ entre manejos.

\section{RESULTADOS E DISCUSSÃO}

Os resultados da densidade do solo (Quadro 1) indicaram, que seis meses após a escarificação, ainda houve diferença significativa entre os manejos de solo, com uma redução da densidade do solo cerca de $3,72 \%$ do PDE em relação ao PD. Machado et al. (1996) destacaram que, mesmo após uma cultura de inverno, persistiram os efeitos, contradizendo Ralisch et al. (2001), que concluíram que a escarificação tem efeitos somente para uma safra de cultura, não tendo efeito residual para outras culturas. Pierce et al. (1992) relataram que o efeito da escarificação pode persistir por anos em um solo franco-arenoso.

Não houve interação entre os manejos e profundidades. Independentemente do manejo do solo, a densidade foi menor na camada superficial de $2,5 \mathrm{~cm}$, o que pode ser atribuído à maior presença de material orgânico nessa camada.

A profundidade de $10 \mathrm{~cm}$ apresentou a densidade mais elevada no PD, enquanto no PDE foi de $15 \mathrm{~cm}$, não diferindo das demais, com exceção da profundidade de $2,5 \mathrm{~cm}$.

A porosidade total e macroporosidade (Quadro 2) não apresentaram diferenças entre os manejos e em profundidade, com exceção da profundidade de $2,5 \mathrm{~cm}$; estes resultados concordam com os obtidos por Inoue et al. (2002) e Costa et al. (2002). Um ponto importante a ser destacado é a grande variação

Quadro 1. Densidade do solo, considerando o manejo e a profundidade

\begin{tabular}{crrr}
\hline Profundidade & PD & PDE & Média \\
\hline cm & \multicolumn{3}{c}{ Mg m$^{-3}$} \\
2,5 & $1,28^{*}$ & $1,17^{*}$ & $1,23 \mathrm{~b}$ \\
5,0 & 1,34 & 1,24 & $1,29 \mathrm{a}$ \\
10,0 & 1,35 & 1,29 & $1,32 \mathrm{a}$ \\
15,0 & 1,34 & 1,32 & $1,33 \mathrm{a}$ \\
20,0 & 1,31 & 1,30 & $1,31 \mathrm{a}$ \\
25,0 & 1,28 & 1,29 & $1,28 \mathrm{a}$ \\
Média & A 1,32 & B 1,27 & \\
CV (\%) & 5,19 & &
\end{tabular}

$\overline{\text { Médias antecedidas pela mesma letra maiúscula, na horizontal, }}$ e seguidas pela mesma letra minúscula, na vertical, não diferem significativamente pelo teste de Duncan a $5 \%$. * Não-significativo. 
nos valores de macroporosidade $(\mathrm{CV}=47,17 \%)$, indicando uma elevada variabilidade espacial, o que pode interferir no crescimento do sistema radicular das plantas e no fluxo de água em profundidade.

Os resultados das determinações da rugosidade superficial do solo (Figura 1) demonstraram que o $\mathrm{PDE}$ apresentou maior rugosidade do que PD, mesmo transcorridos 12 meses da escarificação, indicando que, durante todo esse período, esse microrrelevo poderia estar incrementando a infiltração de água no solo. A manutenção da rugosidade do solo diminui o escoamento superficial e favorece a infiltração, reduzindo os riscos de erosão hídrica (Allmaras et al., 1966).

Em relação ao efeito dos mecanismos sulcadores da semeadora sobre a rugosidade superficial, os mecanismos do tipo DD e do tipo G não diferiram entre si em nenhum dos manejos, graças, provavelmente, à reduzida velocidade de semeadura $\left(3,6 \mathrm{~km} \mathrm{~h}^{-1}\right)$ e à ação dos demais mecanismos da semeadora-adubadora, como rodas limitadoras de profundidade e de fechamento do sulco que promoveram uma acomodação do solo mobilizado.

$O$ percentual do solo coberto com restos culturais de aveia antes da semeadura da soja era de $94 \%$, não diferindo estatisticamente entre os sistemas de manejo (Figura 2), o que indica que a escarificação, seguida da semeadura de uma cultura de cobertura,

Quadro 2. Porosidade total e macroporosidade do solo, considerando o manejo e a profundidade

\begin{tabular}{cccc}
\hline \multirow{2}{*}{ Profundidade } & PD & PDE & Média \\
\hline & & \multicolumn{3}{c}{ m $^{3} \mathrm{~m}^{-3}$} \\
& \multicolumn{3}{c}{ Porosidade total } \\
2,5 & $0,52^{*}$ & $0,55^{*}$ & $0,53 \mathrm{a}$ \\
5,0 & 0,51 & 0,53 & $0,52 \mathrm{ab}$ \\
10,0 & 0,51 & 0,51 & $0,51 \mathrm{~b}$ \\
15,0 & 0,49 & 0,51 & $0,50 \mathrm{~b}$ \\
20,0 & 0,51 & 0,51 & $0,51 \mathrm{~b}$ \\
25,0 & 0,53 & 0,51 & $0,52 \mathrm{~b}$ \\
Média & $0,51^{*}$ & 0,52 & \\
CV $(\%)$ & 6,07 & & \\
& & & \\
& & Macroporosidade \\
2,5 & $0,11^{*}$ & $0,15^{*}$ & $0,13 \mathrm{a}$ \\
5,0 & 0,09 & 0,11 & $0,10 \mathrm{ab}$ \\
10,0 & 0,10 & 0,08 & $0,09 \mathrm{~b}$ \\
15,0 & 0,07 & 0,10 & $0,08 \mathrm{~b}$ \\
20,0 & 0,09 & 0,06 & $0,08 \mathrm{~b}$ \\
25,0 & 0,09 & 0,07 & $0,08 \mathrm{~b}$ \\
Média & $0,10^{*}$ & 0,10 & \\
CV (\%) & $47,17 \%$ & &
\end{tabular}

Médias seguidas pela mesma letra minúscula, na vertical, não diferem significativamente pelo teste de Duncan a $5 \%$. Nãosignificativo. interfere, por curto período, na redução dos restos culturais sobre a superfície do solo.

Quanto ao uso de mecanismos sulcadores do adubo, o sulcador do tipo $G$ apresentou maior incorporação de restos culturais em ambos os sistemas de manejo, em relação ao sulcador do tipo DD, em decorrência do modo de ação e maior profundidade de operação, o que acarreta maior mobilização do solo, resultados que concordam com os encontrados por Silva et al. (2001).

A utilização do sulcador de adubo do tipo disco duplo não apresentou incorporação significativa de restos culturais em ambos os sistemas de manejo, apresentando, em média, $1 \%$ de perda de cobertura, enquanto o sulcador do tipo guilhotina reduziu em 11 e $8 \%$, no PD e PDE, respectivamente. Deve-se considerar que a umidade do solo, no momento da operação, era de $0,275 \mathrm{~kg} \mathrm{~kg}^{-1}$ (friável) e a velocidade

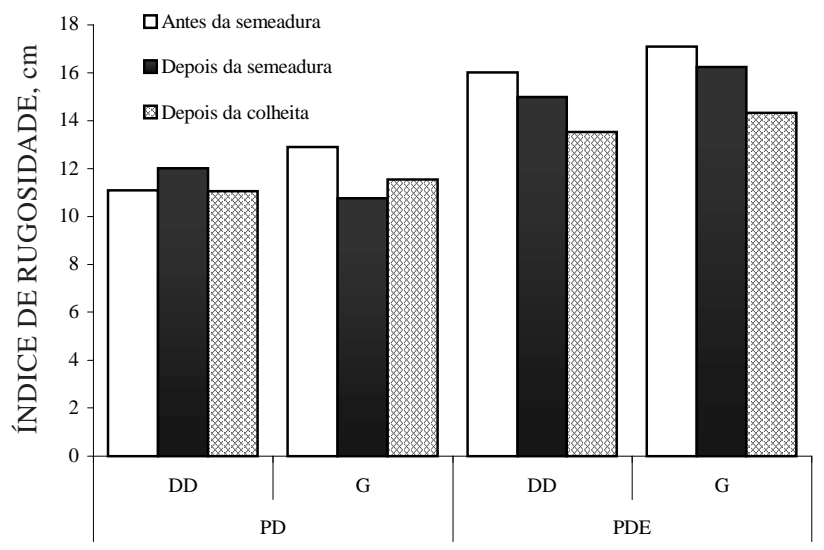

Figura 1. Rugosidade superficial do solo, considerando o manejo de plantio direto (PD), plantio direto escarificado (PDE) e mecanismos sulcadores: guilhotina (G) e duplo disco (DD).

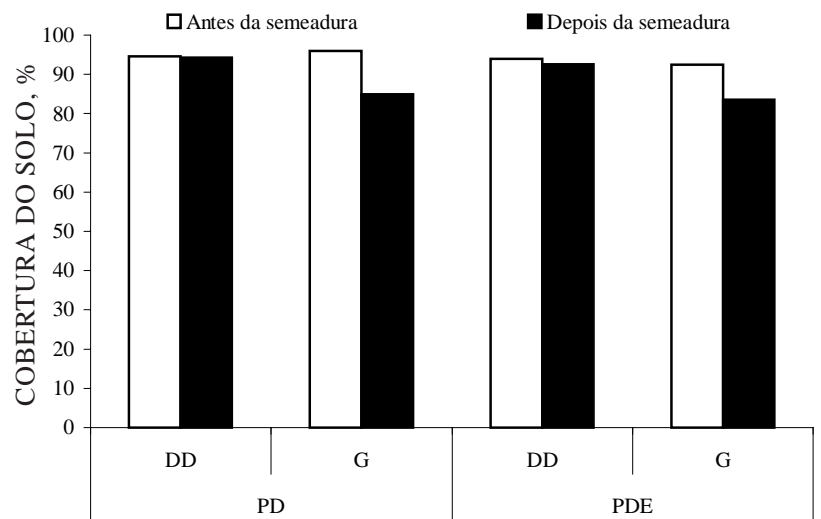

Figura 2. Percentual do solo coberto com restos culturais em diferentes manejos de plantio direto (PD), plantio direto escarificado (PDE) e mecanismos sulcadores: guilhotina (G) e duplo disco (DD). 
de operação de semeadura de apenas $3,6 \mathrm{~km} \mathrm{~h}^{-1}$, por questões operacionais, o que, segundo Klein et al. (2002), contribui para o baixo nível de incorporação. Com o aumento da velocidade de operação da semeadura e maior umidade do solo, ocorreria maior revolvimento do solo e, conseqüentemente, maior incorporação de restos culturais.

A taxa inicial, bem como a taxa final de infiltração de água no solo até $120 \mathrm{~min}$, foi afetada pelo manejo do solo (Figura 3). O PDE apresentou taxa inicial de infiltração 2,2 vezes e taxa final 3,8 vezes superior ao $\mathrm{PD}$, porém sem diferença significativa. O plantio direto apresentou uma taxa final de infiltração de $26,49 \mathrm{~mm} \mathrm{~h}^{-1}$ e o plantio direto escarificado de $99,99 \mathrm{~mm} \mathrm{~h}^{-1}$. Valores superiores da taxa de infiltração em solo escarificado também foram observados por Centurion \& Demattê (1992). Tal comportamento pode ser explicado pelas alterações na estrutura do solo, como menor densidade do solo, e conseqüente aumento da condutividade hidráulica. Segundo Bertol et al. (2001) e Cintra et al. (1983), a taxa de infiltração determinada pelo método dos duplos cilindros concêntricos pode ser superestimada em cerca de 8 a 10 vezes, em relação a que ocorre sob chuva, decorrente da carga hidráulica propiciada pela lâmina de água sobre o solo e da não-formação do selamento superficial.

Neste trabalho, no entanto, com a presença de restos culturais na superfície do solo, em ambos os manejos, o efeito do selamento não ocorreria. Observou-se uma grande dispersão dos pontos indicando uma elevada variabilidade espacial desta propriedade, o que concorda com Vieira et al., (1981), Gurovich \& Stern (1983) e Lima \& Silans (1999).

Em relação à condutividade hidráulica do solo saturado, determinada 12 meses após a escarificação

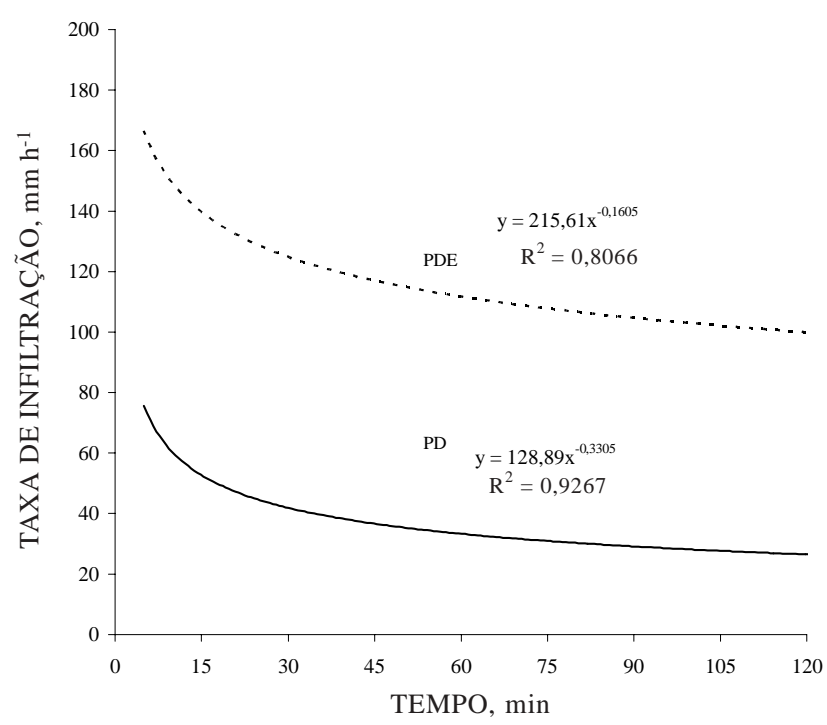

Figura 3. Curvas ajustadas da taxa de infiltração média da água no solo sob plantio direto (PD) e plantio direto escarificado (PDE), seis meses após a escarificação.
(Figura 4), os resultados demonstraram que o PDE apresentava ainda uma capacidade significativamente maior de condução de água, tendo sido os valores de $\mathrm{K}_{0}$ cerca de oito vezes superiores ao $\mathrm{PD}$, o que pode ser atribuído às alterações ocasionadas à estrutura do solo pela escarificação. Anjos et al. (1994) também observaram o mesmo comportamento, quando compararam o PD com preparo do solo com subsolador. Por outro lado, Costa et al. (2002) não encontraram diferença entre o $\mathrm{PD}$, preparo convencional e PDE, para condutividade hidráulica, indicando que o tipo e o manejo do solo, bem como o tipo e as características do implemento de preparo do solo, podem acarretar resultados diferentes, dependendo das complexas interações que ocorrem nesse meio, o solo agrícola.

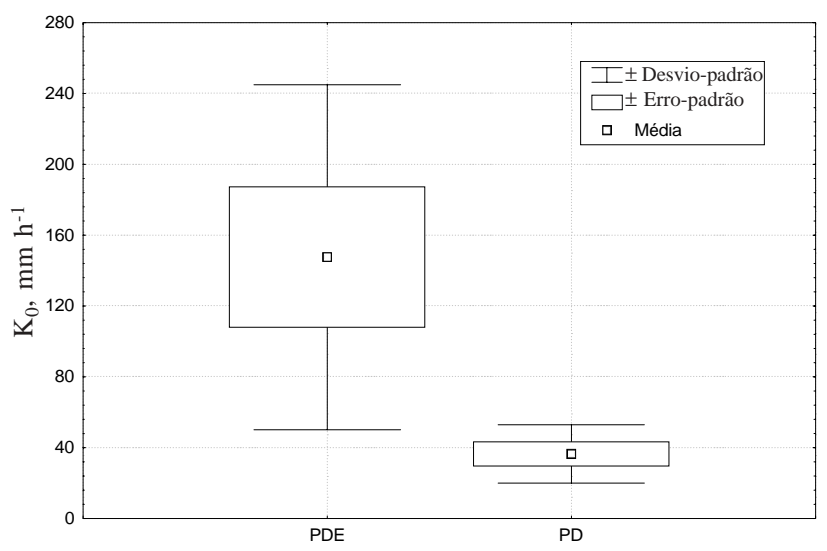

Figura 4. Condutividade hidráulica do solo saturado na camada superficial do solo, sob plantio direto (PD) e plantio direto escarificado, determinada 12 meses após a escarificação.

\section{CONCLUSÕES}

1. A escarificação do solo em PD reduziu a densidade e aumentou a rugosidade superficial , a condutividade hidráulica e a taxa de infiltração de água no solo.

2. O solo sob PDE, transcorridos seis meses após a escarificação, apresentou níveis semelhantes de restos culturais na superfície que o PD.

3. O sulcador de adubo tipo guilhotina incorporou mais restos culturais do que o duplo disco, na operação da semeadura da soja.

\section{LITERATURA CITADA}

ABRÃO, P.U.R.; GOEFERT, C.F.; GUERRA, M.; ELTZ, F.L.F. \& CASSOL, E.A. Efeitos de sistema de preparo do solo sobre características de um Latossolo Roxo distrófico. R. Bras. Ci. Solo, 3:169-172, 1979. 
ALLMARAS, R.R.; BURWELL, R.E.; LARSON, W.E. \& HOLT, R.F. Total porosity and random roughness of the interrow zone as influenced by tillage. Cons. Res. Report., 7:1-22, 1966.

ANJOS, J.T.; UBERTI, A.A.A.; VIZZOTO, V.J.; LEITE, G.B. \& KRIEGER, M. Propriedades físicas em solos sob diferentes sistemas de uso e manejo. R. Bras. Ci. Solo, 18:139-145, 1994.

BERTOL, O.J.; AMADO, T.J.C.; SCHLOSSER, J.F. \& REINERT D.J. Desempenho de mecanismos sulcadores de semeadura sob condições de preparo reduzido do solo. R. Bras. Ci. Solo, 21:257-262, 1997.

BERTOL, I.; BEUTLER, J.F.; LEITE, D. \& BATISTELA, O. Propriedades físicas de um Cambissolo Húmico afetadas pelo tipo de manejo do solo. Sci. Agric., 58:555-560, 2001.

BOLLER, W. Desenvolvimento de complementos para semeadoras em solo sob preparo reduzido. Santa Maria, Universidade Federal de Santa Maria, 1990. 146p. (Tese de Mestrado)

BRAGAGNOLO, N. \& MIELNICZUCK, J. Cobertura do solo por palha de trigo e seu relacionamento com a temperatura e umidade. R. Bras. Ci. Solo, 13:369-373, 1990.

BRITO, L.T.L.; LOUREIRO, B.T.; DENICULI, W.; RAMOS, M.M. \& SOARES, J.M. Influência do método na determinação da taxa de infiltração. R. Bras. Ci. Solo, 20:503-507, 1996.

CARVALHO, F.L.C.; COGO, N.P. \& LEVIEN, R. Eficácia relativa de doses e formas de manejo do resíduo cultural de trigo na redução da erosão hídrica do solo. R. Bras. Ci. Solo, 14:227-234, 1990.

CASTRO, O.M.; LOMBARDI NETO, F.; VIEIRA, S.R. \& DECHEN, S.C.F. Sistemas convencionais e reduzidos de preparo do solo e as perdas por erosão. R. Bras. Ci. Solo, 10:167-171, 1986.

CENTURION, J.F. \& DEMATTÊ, J.L.I. Sistema de preparo de solos de cerrado: Efeitos nas propriedades físicas e na cultura do milho. Pesq. Agropec. Bras., 27:315-324, 1992.

CHAVES, H.M.L.; ORLOWSKI, E. \& ROLOFF, G. Previsão da infiltração sob dinâmicas de selamento superficial. R. Bras. Ci. Solo, 17:141-147, 1993.

CINTRA, F.L.D.; MIELNICZUK, J. \& SCOPEL, I. Caracterização do impedimento mecânico em um Latossolo Roxo do Rio Grande do Sul. R. Bras. Ci. Solo, 7:323-327, 1983.

COGO, N.P.; MOLDENHAUER, W.C. \& FOSTER, G.R. Soil loss reductions form conservation tillage practices. Soil Sci. Soc. Am. J., 48:368-373, 1984.

COSTA, F.S.; ALBUQUERQUE, J.A.; BAYER, C. \& WOBETO, C. Sistemas de manejo do solo e propriedades físicas de um Latossolo Bruno: Efeitos de 20 anos. In: REUNIÃO BRASILEIRA DE MANEJO E CONSERVAÇÃO DO SOLO E DA ÁGUA, 14., Cuiabá, 2002. Resumos Expandidos. Cuiabá, Sociedade Brasileira de Ciência do Solo, 2002. CDROM

DALLMEYER, A.U. Avaliação energética e desempenho operacional de equipamentos de preparo do solo. Botucatu, Universidade Estadual Paulista, 1994. 156p. (Tese de Doutorado)
DENARDIN, J.E. Preparo conservacionista do solo. Plantio Direto, 5:2, 1987.

ELTZ, F.M.L.; ORLOWSKI, E. \& ROLOFF, G. Efeito de sistema de preparo nas propriedades físicas e químicas de um Latossolo Bruno álico, R. Bras. Ci. Solo, 13:259-267, 1989.

EMPRESA BRASILEIRA DE PESQUISA AGROPECUÁRIA EMBRAPA. Centro Nacional de Pesquisa de Solos. Manual de Métodos de Análise de Solo. 2.ed. Rio de Janeiro, 1997. 212p.

GAVANDE, A.G. Física de suelos: princípios y aplicaciones. 5.ed. Mexico, Limusa, 1986, 351p.

FOSTER, G.R. Modeling the erosion process. In: BASSELMAN, J.A., ed. Hidrological modelling of small watersheds. St. Joseph, American Society of Agricultural Engineers. 1982. p.297-300.

GUROVICH, L.A. \& STERN, J. Variabilidad especial de la velocidad de infiltración en el suelo. II. Análisis geostadístico y estructura espacial. Ci. Invest. Agric., 10:271-278, 1983.

INOUE, T.T.; ARAÚJO, M.A.; TORMENA, C.A.; ESTEVES, N.; MIGNOSO, V. \& LEITE, J.C. Influência da escarificação em propriedades físicas de um Latossolo Vermelho distroférrico após 13 anos de plantio direto. In: REUNIÃO BRASILEIRA DE MANEJO E CONSERVAÇÃO DO SOLO E DA ÁGUA, 14., Cuiabá, 2002. Resumos Expandidos. Cuiabá: Sociedade Brasileira de Ciência do Solo, 2002. CDROM

KERTZMANN, F.F. Modificações na estrutura e no comportamento de um Latossolo Roxo provocado pela compactação. São Paulo, Universidade de São Paulo, 1996. 153p. (Tese de Doutorado)

KLEIN, V.A.; SIOTA, T.A.; ANESI, A.L. \& BARBOSA, R. Efeito da velocidade na semeadura direta de soja. Eng. Agríc. 22:75-82, 2002.

KOCHHANN, R.A. \& DENARDIN, J.E. Implantação e manejo do sistema plantio direto. Passo Fundo, EMBRAPA-CNPT, 2000. 36p.

KOSTIAKOV, A.N. On the dynamics of the coefficient of waterpercolation in soils and on the necessity for studying it from a dinamics point of view for purposes of amelioration. Trans. Comm. Intern. Soc. Soil Sci., 6:17-21, 1932.

LAFLEN, J.M.; AMEMIYA, M. \& HINTZ, E.A. Measuring crop residue cover. J. Soil Water Conserv., 36:341-343, 1981.

LEVIEN, R.; COGO, N.P. \& ROCKENBACH, C.A. Erosão na cultura do milho em diferentes sistemas de cultivo anterior e métodos de preparo do solo. R. Bras. Ci. Solo, 14:73-80, 1990.

LIMA, C.A.G. \& SILANS, A.P. Variabilidade espacial da infiltração de água no solo. Pesq. Agropec. Bras., 34:23112320,1999

MACHADO, R.L.T.; TURATTI, A.L.; MACHADO, A.L.T.; ALONÇO, A.S. \& REIS, A.V. Estudos de parâmetros físicos em solo de várzea, entes e após escarificação. R. Bras. Agroc., $2: 175-178,1996$ 
PIERCE, F.J.; FORTIN, M.C. \& STATON, M.J. Immediate and residual effects of zone-tillage in rotation with no-tillage on soil physical properties and corn performance. Soil Till. Res., 30:149-165, 1992.

RALISCH, R.; TAVARES FILHO, J. \& ALMEIDA, M.V.P. Avaliação de um solo argiloso sob plantio direto de uma escarificação na evolução da resistência do solo a penetração In: CONGRESSO BRASILEIRO DE ENGENHARIA AGRÍCOLA, 30., Foz do Iguaçu, 2001. Resumo expandido. Foz do Iguaçu, CONBEA, 2001. CD-ROM

RESCK, D.V.S. O plantio direto como alternativa de sistema de manejo e conservação do solo e da água na região dos cerrados. In: CONGRESSO BRASILEIRO DE CIÊNCIA DO SOLO, 27., Brasília, 1999. Resumo expandido. Brasília, Sociedade Brasileira de Ciência do Solo, 1999. CD-ROM

ROMEIRO, A.R. Meio ambiente e dinâmica de inovações na agricultura. Annablume, 1998.

SECCO, D. \& REINERT, D.J. Efeitos imediato e residual de escarificadores em Latossolo Vermelho-Escuro sob plantio direto. Eng. Agric., 16:52-61, 1997.
SILVA, A.R.B.; BENEZ, S.H.; MAHL, D.; LEITE, M.A.S.; PONTES, J.R.; GREGO, C.R.; MARQUES, J.P. \& COSTA, A.M. Avaliação de uma semeadora-adubadora de plantio direto em função de diferentes mecanismos sulcadores e velocidades de deslocamento. In: CONGRESSO BRASILEIRO DE ENGENHARIA AGRÍCOLA, 30., Foz do Iguaçu, 2001. Resumo expandido. Foz do Iguaçu, CONBEA, 2001. CD-ROM

SILVA, I.F. Efeitos de sistemas de manejo e tempo de cultivos sobre as propriedades físicas de um Latossolo. Porto Alegre, Universidade Federal do Rio Grande do Sul. 1980. 70p. (Tese de Mestrado)

VASQUEZ, E.V. \& DE MARIA, I.C. Influencia del Laboreo sobre la rugosidad del suelo y la retención de agua en un Ferrasol. In: CONGRESSO BRASILEIRO DE CIÊNCIA DO SOLO, 29., Ribeirão Preto, 2003. Resumo expandido. Ribeirão Preto, Sociedade Brasileira de Ciência do Solo, 2003. CDROM

VIEIRA, S.R.; NIELSEN, D.R. \& BIGGAR, J.W. Spatial variability of field-measured infiltration rate. Soil Sci. Soc. Am. J., 45:1040-1048, 1981. 